\title{
Neurotrophic Factors Mediate Memory Enhancing Property of Ethanolic Extract of Liriope platyphylla in Mice
}

\author{
Jung Hyun Mun a,1, Sang Gon LeE ${ }^{\mathrm{a}, 1}$, Dong Hyun KIM ${ }^{\mathrm{b}}$, Ji Wook Jung ${ }^{\mathrm{e}}$, Seungjoo LEE ${ }^{\mathrm{b}}$, \\ Byung Hoon Yoon ${ }^{b}$, Bum Young SHIN ${ }^{d}$, Sun Ho KIM ${ }^{b}$, and Jong Hoon RYU ${ }^{\mathrm{a}, \mathrm{b}, \mathrm{c}}$ * \\ ${ }^{a}$ Department of Oriental Pharmaceutical Science, \\ ${ }^{d}$ Department of Pharmaceutical Science, \\ ${ }^{c}$ Kyung Hee East-West Pharmaceutical Research Institute, College of Pharmacy, \\ ${ }^{b}$ Department of Life and Nanopharmaceutical Science, Kyung Hee University, \\ Hoeki-dong, Dongdaemoon-Ku, Seoul 130-701, Korea \\ e Department of Herbal Medicinal Resource, College of Health and Welfare, \\ Daegu Haany University, Gyeongsan 712-715, Korea \\ ${ }^{1}$ These authors contributed equally to this paper
}

(Received 7 June 2007; Accepted 26 June 2007)

\begin{abstract}
The roots of Liriope platyphylla (Liliaceae) are widely used in traditional Chinese medicine. In the present study, we investigated the effects of ethanol (70\%) extract of the roots of Liriope platyphylla (ELP70) on learning and memory using behavioral and immunohistochemical methods in mice. Control animals were treated with vehicle (10\% Tween 80 ). With sub-chronic treatments of ELP70 (p.o.) for 14 days, the latency time was significantly increased compared with that of the vehicle-treated control group (50, 100 and $200 \mathrm{mg} / \mathrm{kg} ; P<0.05$ ). Moreover, immunopositive cells for brain derived neurotrophic factor (BDNF) were significantly increased in the hippocapmpal dentate gyrus and CA1 regions after ELP70 treatments for 14 days $(50,100$ and $200 \mathrm{mg} / \mathrm{kg} ; P<$ $0.05)$. In addition, those cells for nerve growth factor (NGF) were also increased in the hippocapmpal dentate gyrus region $(50,100$ and $200 \mathrm{mg} / \mathrm{kg} ; P<0.05)$. These results suggest that the sub-chronic administration of ELP70 improves learning and memory, and that their beneficial effects are mediated, in part, by the enhancement of BDNF or NGF expression.
\end{abstract}

Keywords $\square$ Liriope platyphylla, Memory, Passive avoidance test, NGF, BDNF

\section{INTRODUCTION}

Brain derived neurotrophic factor (BDNF) and nerve growth factor (NGF) are member of the neurotrophin family known to play important roles in the survival, growth, and maintenance of neurons during development (Leibrock et al., 1989; Barde, 1994). Several lines of evidences suggest that BDNF and NGF are essential to modulate synaptic-plasticity in the adult brain. For example, BDNF regulates axonal and dendritic branching and remodeling (Shimada et al., 1998; Lom \& Cohen-Cory, 1999; McAllister et al., 1997; Yacoubian \& Lo, 2000), synaptogenesis in arborizing axon terminals (Alsina et al., 2001), the

*Corresponding author

Tel: $+82-2-961-9230, \quad$ Fax: $+82-2-966-3885$

E-mail: jhryu63@khu.ac.kr efficacy of synaptic transmission (Lohof et al., 1993; Kang \& Schuman, 1995; Boulanger \& Poo, 1999; Kafitz et al., 1999), and the functional maturation of excitatory and inhibitory synapses (Seil \& Drake-Baumann, 2000; Rutherford et al., 1998; Vicario-Abejon et al., 1998). BDNF gene deletion or inhibition produces a deficit in long-term potentiation (Figurov et al., 1996; Kang et al., 1997). Moreover, NGF promotes the survival and functioning of cholinergic neurons in the basal forebrain (Chen et al., 1997). These neurons project to the hippocampus and are believed to be important for memory processes, which are specifically affected in Alzheimer's disease. Thus, BDNF and NGF play critical roles in the learning and memory process (Nguyen \& Kandel, 1996; Chen et al., 1997).

Liriope platyphylla Wang et Tang (Liliaceae) is widely employed for respiratory disease including cough and sputum in traditional Chinese prescriptions. With regards to the phar- 
macological effect of L. platyphylla, antibacterial and anticancer effects have been reported (Kim et al., 2002). Moreover, buthanol fraction of L. platyphylla enhances the nerve growth factor (NGF) synthesis in the primary astrocyte, and NGF released induces the neurite outgrowth of PC12 cells (Hur et al., 2004). These observations suggest a possibility that $L$. platyphylla affect in memory process through the enhancement of neurotrophic factors. In the present study, we want to confirm this possibility by the treatment with ethanolic extract of Liriope platyphylla (ELP70) using behavioral and immunohistochemical methods. We employed the passive avoidance task for learning and memory behavior in mice and investigated the changes of BDNF and NGF expression in the hippocampal formation using immunohistochemical methods.

\section{MATERIALS AND METHODS}

\section{Animals}

Male ICR mice (25-30 g) were purchased from the Orient Co., Ltd, a branch of Charles River Laboratories (Seoul, Korea). The animals were housed 5 or 6 per cage, allowed access to water and food ad libitum, and maintained under a constant temperature $\left(23 \pm 1^{\circ} \mathrm{C}\right)$ and humidity $(60 \pm 10 \%)$ under a 12-h light/ dark cycle (light on 07.30 - 19.30 h). Animal treatment and maintenance were carried out in accordance with the Principle of Laboratory Animal Care (NIH publication No. 8523, revised 1985) and the Animal Care and Use Guidelines of Kyung Hee University, Korea.

\section{Materials}

Anti-NGF antibody and anti-BDNF antibody were purchased from Abcam (UK), and Santa Cruz Biotech (USA), respectively. The roots of Liriope platyphylla were obtained from an herbal supplier in Seoul, Korea, and voucher specimens (KHUOPS-03-19) were deposited at the herbarium of the College of Pharmacy, Kyung Hee University (Seoul, Korea). The material was authenticated by Emeritus Professor Chang Soo Yook of the Department of Oriental Pharmaceutical Science, College of Pharmacy, Kyung Hee University. All the other materials were of the highest grade commercially available.

\section{Sample preparation}

The dried the roots of Liriope platyphylla $(1 \mathrm{~kg})$ were extracted with $70 \% \mathrm{EtOH}$ three times under an ultrasonic apparatus. The ethanolic solution obtained was filtered, concen- trated in a water bath under vacuum, removed solvent in vacuum, frozen and lyophilized (Eyela, model FDU-2000, Japan) to yield the ethanolic extract (yield 12.5\%), which was then stored at $-20^{\circ} \mathrm{C}$ until required. ELP70 was freshly suspended in $10 \%$ Tween 80 solution and orally administered for 14 days.

\section{Passive avoidance task}

Passive avoidance performance was carried out in two identical light and dark square boxes $(20 \times 20 \times 20 \mathrm{~cm}$, respectively) separated by a guillotine door $(5 \times 5 \mathrm{~cm})$, as described in our previous report (Kim et al., 2006). The illuminated compartment contained a $50 \mathrm{~W}$ bulb, and the floor of the non-illuminated compartment was composed of $2 \mathrm{~mm}$ stainless steel rods spaced $1 \mathrm{~cm}$ apart. Mice were initially placed in the illuminated compartment for the acquisition trial and the door between the two compartments was opened $10 \mathrm{~s}$ later. When mice entered the dark compartment, the door automatically closed and an electrical foot shock $(0.25 \mathrm{~mA})$ of $3 \mathrm{~s}$ durations was delivered through the stainless steel rods. One hour after the final administration of ELP70 $(25,50100$, or $200 \mathrm{mg} / \mathrm{kg}$, p.o.) on the 14th day, the mice were placed in the illuminated compartment for the acquisition trials. Control animals were treated with $10 \%$ Tween 80 solution only. Twenty-four hours after acquisition trial, the mice were again placed in the illuminated compartment for the retention trials. The time taken for a mouse to enter the dark compartment after door opening was measured as latency times in both acquisition and retention trials.

\section{Tissue preparation}

After the passive avoidance task, mice were anesthetized with pentobarbital sodium $(60 \mathrm{mg} / \mathrm{kg}$, i.p. $)$ and perfused transcardially $0.1 \mathrm{M}$ phosphate buffer $(\mathrm{pH} 7.4)$ followed by icecold $4 \%$ paraformaldehyde. Brains were removed and postfixed in phosphate buffer $(0.05 \mathrm{M}, \mathrm{pH} 7.4)$ containing $4 \%$ paraformaldehyde overnight and then immersed in $30 \%$ sucrose solution (in $0.05 \mathrm{M}$ phosphate-buffered saline), and stored at $4^{\circ} \mathrm{C}$ until sectioning. The frozen brain were coronally sectioned on a cryostat $(30 \mu \mathrm{m})$ and then stored in storing solution at $4^{\circ} \mathrm{C}$.

\section{Immunohistochemistry}

Free floating sections were incubated for $24 \mathrm{~h}$ in $\mathrm{PBS}\left(4^{\circ} \mathrm{C}\right)$ containing anti- NGF antibody (1:1000 dilution) or anti-BDNF antibody (1:1000 dilution), $0.3 \%$ Triton X-100, $0.5 \mathrm{mg} / \mathrm{ml}$ of 
bovine serum albumin, and $1.5 \%$ normal horse serum. The sections were then incubated for 90 min with biotinylated secondary antibody (1:200 dilution, Vector, Burlingame, CA, USA), and then with avidin-biotin-peroxidase complex (1:100 dilution, Vector, Burlingame, CA, USA) for $1 \mathrm{~h}$ at room temperature. Finally, the sections were reacted with $0.02 \% 3,3$ 'diaminobenzidine and $0.01 \% \mathrm{H}_{2} \mathrm{O}_{2}$ for about $3 \mathrm{~min}$. After each incubation step, sections were washed three times with PBS. Sections were mounted on gelatin-coated slides, dehydrated in ascending alcohol concentrations and cleared in xylene.

\section{Quantitation of data and Statistical Analysis}

Immunopositive cells were counted with a computerized image analysis system (Leica Microsystems AG, Wetzlar, Germany). Cell counts were carried out in the dentate gyrus and CA1 regions in hippocampal area in five mice per group and in a blinded manner, which allowed statistical analysis. Values are expressed as mean \pm S.E.M. Data were analyzed by one-way analysis of variance (ANOVA) followed by the Student-Newman-Keuls test for multiple comparisons. Statistical significance was set at $P<0.05$.

\section{RESULTS}

\section{Effect of ELP70 on the passive avoidance task}

We assessed whether ELP70 improves memory function in the passive avoidance task which is largely dependent on longterm memory. When placed on the bright side of a step-through box, mice quickly entered into the dark compartment. When mice were conditioned using a mild foot shock $(0.25 \mathrm{~mA})$ after entering the dark compartment, they hesitated to re-enter the dark compartment when tested $24 \mathrm{~h}$ later. The sub-chronic treatment of ELP $(25,50,100$, or $200 \mathrm{mg} / \mathrm{kg})$ showed a significant group effect on the step-through latency in retention trial $[F(4,45)=3.74, P<0.05]$ (Fig. 1). The step-through latencies were significantly longer by ELP70 treatment for 14 days (50, 100 , and $200 \mathrm{mg} / \mathrm{kg}$ ) compared with those of vehicle-treated control group $(P<0.05$, Fig. 1). In the acquisition trial, there were no significant differences of step-through latency across all groups.

\section{Effect of ELP70 on the immunoreactivities of BDNF and NGF}

With the sub-chronic administration of ELP70, BDNF immunoreactive cells were markedly increased within the hippocampal CA1 and dentate gyrus regions in a dose dependant

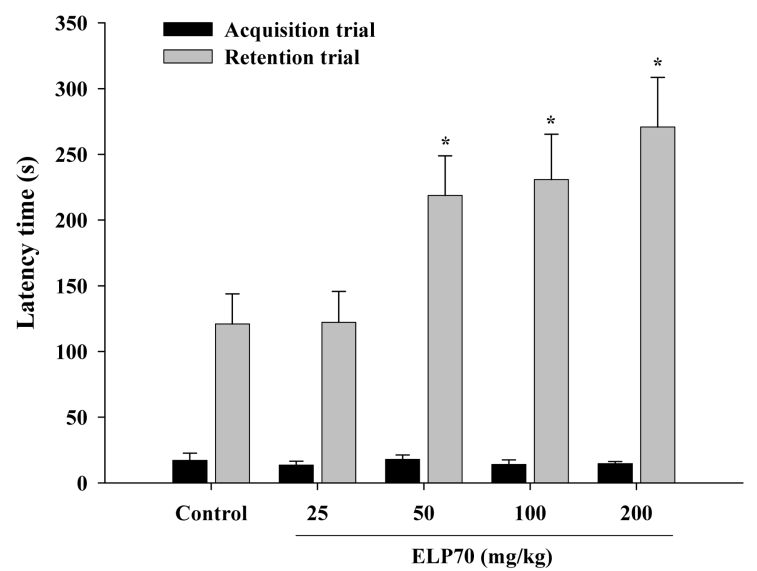

Fig. 1. Effect of sub-chronic administration of ethanolic extract of Liriope platyphylla (ELP70) in the passive avoidance task. ELP70 was administered orally for 14 days. The last administration of ELP70 $(25,50,100$, and $200 \mathrm{mg} / \mathrm{kg}$, p.o. $)$ or the same volume of $10 \%$ Tween 80 solution was accomplished $60 \mathrm{~min}$ before the acquisition trials. The retention trials were carried out $24 \mathrm{~h}$ after acquisition trials. Data represent means \pm S.E.M $(n=10) .{ }^{*} P<0.05$, compared with the vehicle control group.

manner ( $P<0.05$, Fig. 2). Especially, BDNF positive cells in dentate gyrus region were higher than those in CA1 region. The NGF immunoreactive cells were also increased by treatment of ELP70 in dentate gyrus region $(P<0.05$, Fig. 3). However, those cells were not observed in CA1 region (Fig. 3A1-D1).

\section{DISCUSSION}

In the present study, it was found that sub-chronic treatment with ELP70 enhanced memory performances in the passive avoidance task in mice. Furthermore, ELP70 also increased the expressions of neurotrophic factors including NGF and BDNF in the hippocampal formation. These results suggest that the memory enhancing properties of ELP70 may be associated with the increase of expressions of neurotrophic factors in the hippocampal formation.

Previously, we observed that there were no significant changes in the latency time in the passive avoidance test with an acute single administration of ELP70 (dose ranges; 25-200 $\mathrm{mg} / \mathrm{kg}$, p.o.) (data not shown). Recently, Hur et al (2004) reported that buthanol fraction of L. platyphylla enhanced the NGF synthesis in the primary astrocyte, and NGF released induced the neurite outgrowth of PC12 cells. Therefore, we assumed that prolonged administration of ELP70 enough for inducing neurotrohpic factor expressions could affect learning 

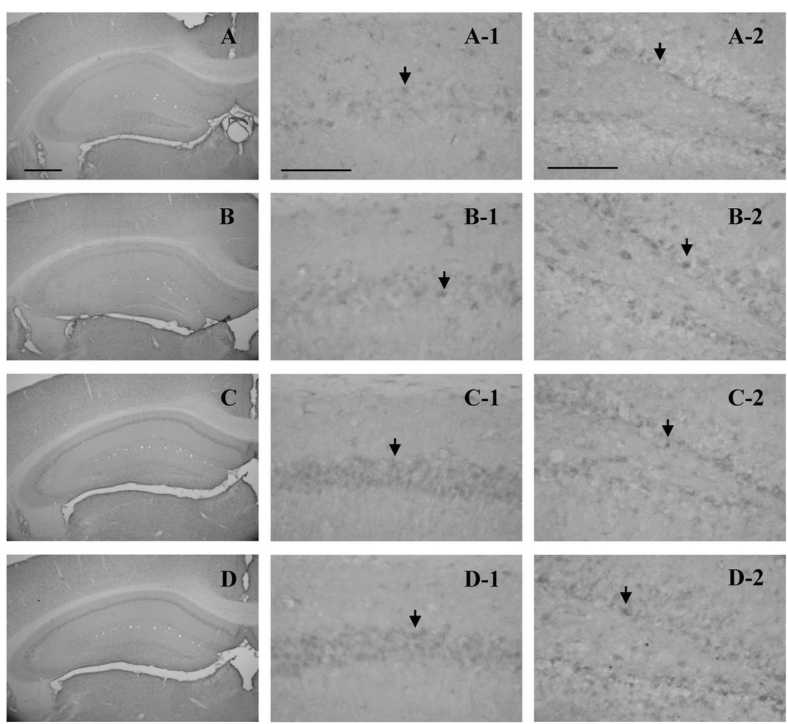

E

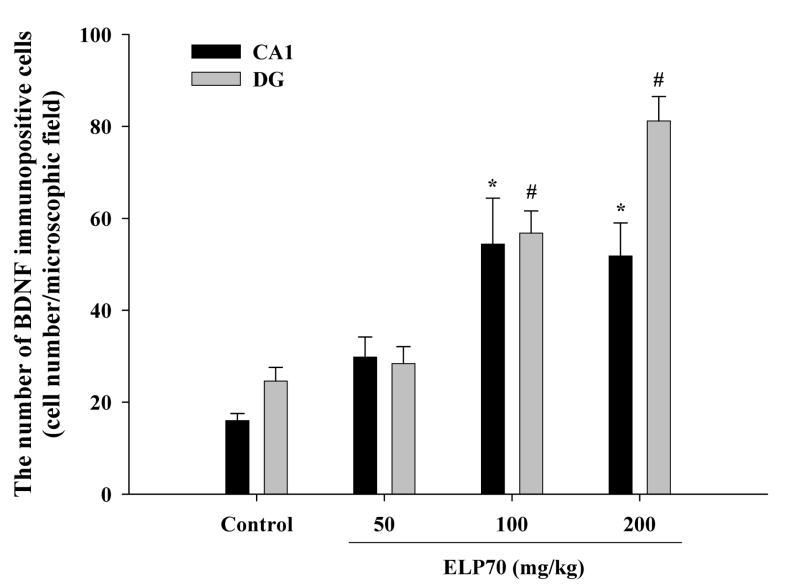

Fig. 2. Representative photomicrographs of the BDNF positive cells in the hippocampal (A-D), dentate gyrus (A-1, B-1, C-1, and $\mathrm{D}-1), \mathrm{CA} 1$ regions (A-2, B-2, C-2, and $\mathrm{D}-2)$, and the number of BDNF positive cells in the denate gyrus (DG) and CA1 regions (E) after administration of vehicle (A-A-2) or ethanolic extract of Liriope platyphylla (ELP70) at $50 \mathrm{mg} / \mathrm{kg}$ (B-B-2), $100 \mathrm{mg} / \mathrm{kg}$ (C-C-2), or $200 \mathrm{mg} / \mathrm{kg}$ (D-D-2) for 14 days. Data represent means \pm S.E.M $(n=5)$. ${ }^{*},{ }^{\#} P<0.05$, compared with the vehicle control group. The bar represents $100 \mu \mathrm{m}$ for A-D (magnification: $40 \mathrm{X}$ ). The bar represents 50 ìm for others (magnification: $400 \mathrm{X}$ ).

and memory. To confirm this hypothesis, the ELP70 was administered for 14 days. In the present study, sub-chronic administration of ELP70 increased the latency time in the passive avoidance task versus vehicle-treated control group in a dose dependant manner. However, during the acquisition trial, no differences in latencies were observed between any groups, demonstrating no significant effects of ELP70 on the general
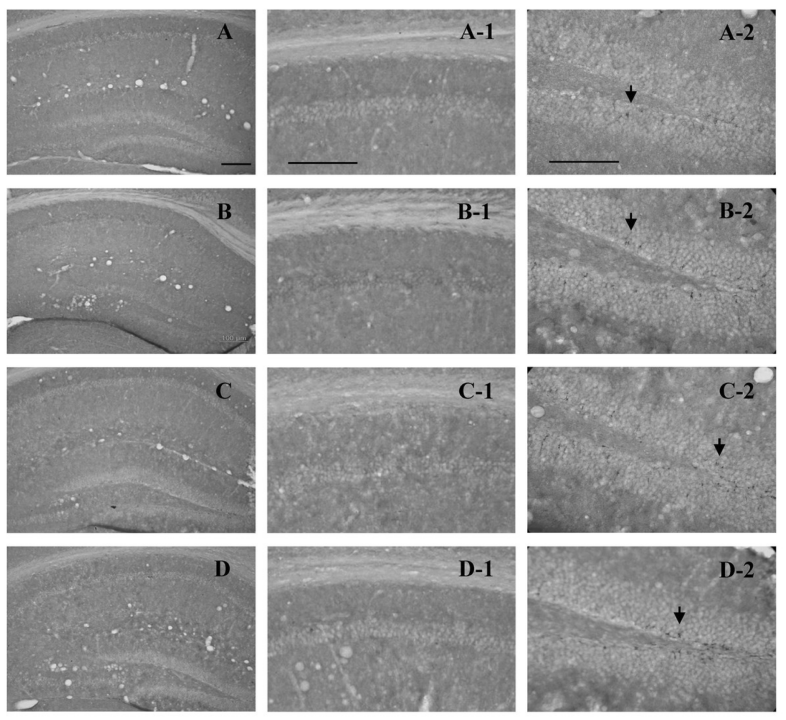

$\mathbf{E}$

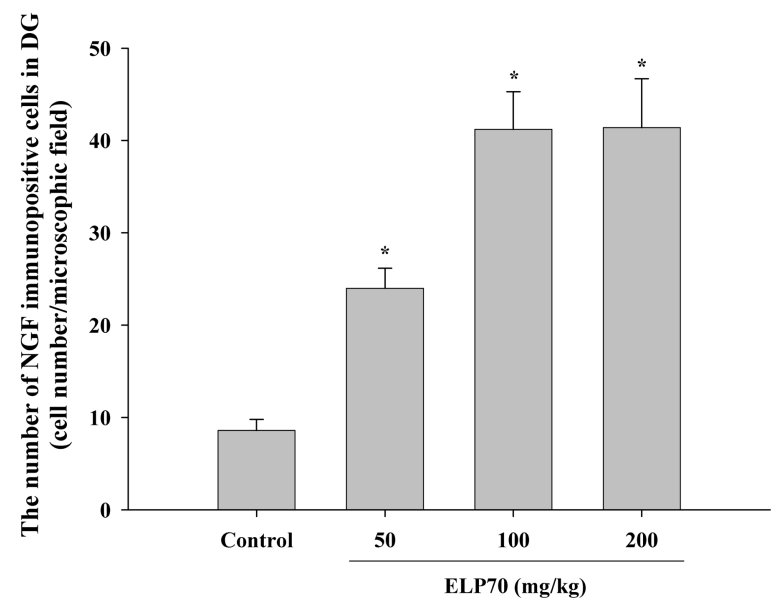

Fig. 3. Representative photomicrographs of the NGF positive cells in the hippocampal (A-D), dentate gyrus (A-1, B-1, C-1 D-1), CA1 regions (A-2, B-2, C-2, D-2), and the number of NGF positive cells in the denate gyrus region (E) after administration of vehicle (A-A-2) or ethanolic extract of Liriope platyphylla (ELP70) at $50 \mathrm{mg} / \mathrm{kg}$ (B-B-2), $100 \mathrm{mg} / \mathrm{kg}$ (C-C-2), or $200 \mathrm{mg} / \mathrm{kg}$ (D-D-2) ethanolic extract of Liriope platyphylla (ELP70) for 14 days. Data represent means \pm S.E.M $(n=5) .{ }^{*} P<$ 0.05 , compared with the vehicle control group. The bar represents $100 \mathrm{im}$ for A-D (magnification: $40 \mathrm{X}$ ). The bar represents 50 ìm for others (magnification: $400 \mathrm{X}$ ).

behaviors. These behavioral results suggest that sub-chronic treatment of ELP70 might increase the expression of some molecules related with memory performances, such as neurotrophic factors, because single treatment of ELP70 did not show any significant changes in the passive avoidance task.

NGF is the first identified neurotrophic factor and displays a 
restricted target population. In the peripheral nervous system, it acts on sympathetic neurons as well as sensory neurons involved in nociception and temperature sensation (Cahill et al., 2003). In the central nervous system, on the other hand, NGF promotes the survival and functioning of cholinergic neurons in the basal forebrain, suggesting that the increase of NGF expression is related with memory performances (Chen et al., 1997; Gutierrez et al., 1997). If ELP70 induces NGF expression in vivo, it would be involved in the memory enhancement because buthanol fraction of L. platyphylla enhances the NGF synthesis in the primary astrocyte (Hur et al., 2004). To confirm this idea, we carried out NGF immunostaining in the hippocampal region. The sub-chronic ELP70 treatment dramatically increased NGF expressions in the hippocampal dentate gyrus region. The immunopostive cells for NGF in the ELP70-treated group were increased to approximately $297 \%$ (50 mg/kg), $477 \%(100 \mathrm{mg} / \mathrm{kg})$, and $481 \%(200 \mathrm{mg} / \mathrm{kg})$ of the vehicletreated control group. In the CA1 region, however, there are no changes of NGF immunopositive cells. Although we did not know the reasons why the NGF expression was not changed in the CA1 region, the enhancement of NGF expression is likely involved in the ELP70-induced memory enhancement. This result is also supported by which exogenous NGF reversed the age-dependent changes in cholinergic basal forebrain neurons and improved performance in spatial memory tasks (Bruno et al., 2004).

BDNF has emerged as a major regulator of synaptic transmission and plasticity at adult synapses in many regions of the CNS. This unique role within the neurotrophin family fits with the widespread distribution of BDNF and the co-localization of BDNF and its receptor, TrkB, at glutamate synapses. The versatility of BDNF is emphasized by its contribution to a range of adaptive neuronal responses including long-term potentiation (LTP), long-term depression (LTD), certain forms of short-term synaptic plasticity, as well as homeostatic regulation of intrinsic neuronal excitability (Desai et al., 1999; Asztely et al., 2000; kegaya et al., 2002; Maffei, 2002). Moreover, BDNF plays a vital role in neuronal survival, growth (Lindsay et al., 1994) and synaptic plasticity (Thoenen, 1995; Schinder and Poo, 2000). Some studies have shown that hippocampal BDNF expression increases during spatial learning (Gooney et al., 2002; Mizuno et al., 2000), whereas BDNF knockout mice show deficits in spatial learning (Linnarsson et al., 1997) and synaptic plasticity (Korte et al., 1995). Moreover, administration of BDNF improves performance in a spatial memory task (Alonso et al., 2002; Cirulli et al., 2004). If sub-chronic ELP70 treatment can affect the BDNF expression in the hippocampal area, BDNF would also be involved in ELP70-related learning and memory performances. ELP70 treatment increased BDNF to approximately $230 \%(100 \mathrm{mg} / \mathrm{kg})$ and $330 \%(200 \mathrm{mg} / \mathrm{kg})$ of the vehicle-treated control group in the hippocampal dentate gyrus region. On the contrary to the NGF expression, in the hippocampal CA1 region, BDNF expression also increased to $340 \%(100 \mathrm{mg} / \mathrm{kg})$ and $323 \%(200 \mathrm{mg} / \mathrm{kg})$ of the vehicletreated control group, respectively. Although we did not find whether the blockade of the increase of NGF or BDNF expressions by ELP70 can deteriorate memory performances, it is likely that sub-chronic administration of ELP70 would enhance memory performances through the increase of NGF or BDNF expressions. Until now, however, it is unclear that the same mechanism or same compound is involved in the increase of NGF and BDNF expressions related with the memory performances. We are currently working on the isolation of active compound in ELP70 using an activity-guided fractionation approach.

From the above behavioral and immunohistochemical data, it can be concluded that ELP70 has an ability to improve learning and memory through the increase of NGF and BDNF expressions in the hippocampus.

\section{ACKNOWLEDGEMENTS}

This research was supported by a grant funded by Seoul Research and Business Development Program (10524).

\section{REFERENCES}

Alonso, M., Vianna, M.R., Izquierdo, I., Medina, J.H. (2002). Signaling mechanisms mediating BDNF modulation of memory formation in vivo in the hippocampus. Cell. Mol. Neurobiol. 22, 663-674.

Alsina, B., Vu, T., Cohen-Cory, S. (2001). Visualizing synapse formation in arborizing optic axons in vivo: dynamics and modulation by BDNF. Nat. Neurosci. 4, 1093-1101.

Asztely, F., Kokaia, M., Olofsdotter, K., Ortegren, U., Lindvall, O. (2000). Afferent-specific modulation of short-term synaptic plasticity by neurotrophins in dentate gyrus. Eur. J. Neurosci. 12, 662-669.

Barde, Y.A. (1994). Neurotrophins: a family of proteins supporting the survival of neurons. Prog. Clin. Biol. Res. 390, 45-56.

Boulanger, L., Poo, M.M. (1999). Presynaptic depolarization facilitates neurotrophin-induced synaptic potentiation. Nat. Neurosci. 2, 346-351.

Bruno, M.A., Clarke, P.B., Seltzer, A., Quirion, R., Burgess, K., Cuello, A.C., Saragovi, H.U. (2004). Long-lasting rescue of age-associated deficits in cognition and the CNS cholinergic phenotype by a partial agonist peptidomimetic ligand of TrkA. 
J. Neurosci. 24, 8009-8018.

Cahill, C.M., Dray, A., Coderre, T.J. (2003). Intrathecal nerve growth factor restores opioid effectiveness in an animal model of neuropathic pain. Neuropharmacology 45, 543-552.

Chen, K., Nishimura, M., Armanini, M., Crowley, C., Spencer, S., Phillips, H. (1997). Disruption of a single allele of the nerve growth factor gene results in atrophy of basal forebrain cholinergic neurons and memory deficits. J. Neurosci. 17, 72887296.

Cirulli, F., Berry, A., Chiarotti, F., Alleva, E. (2004). Intrahippocampal administration of BDNF in adult rats affects short-term behavioral plasticity in the Morris water maze and performance in the elevated plus-maze. Hippocampus. 14, 802-807.

Desai, N.S., Rutherford, L.C., Turrigiano, G.G. (1999). BDNF regulates the intrinsic excitability of cortical neurons. Learn. Mem. 6, 284-291.

Figurov, A., Pozzo-Miller, L.D., Olafsson, P., Wang, T., Lu, B. (1996). Regulation of synaptic responses to high-frequency stimulation and LTP by neurotrophins in the hippocampus. Nature. 381, 706-709.

Gooney, M., Shaw, K., Kelly, A., O’Mara, S.M., Lynch, M.A. (2002). Long-term potentiation and spatial learning are associated with increased phosphorylation of TrkB and ERK in dentate gyrus: evidence for a role for BDNF. Behav. Neurosci. 116, 455-463.

Gutierrez, H., Miranda, M.I., Bermudez-Rattoni, F. (1997). Learning impairment and cholinergic deafferentation after cortical nerve growth factor deprivation. J. Neurosci. 17, 3796-3803.

Hur, J., Lee, P., Kim, J., Kim, A.J., Kim, H., Kim, S.Y. (2004). Induction of nerve growth factor by butanol fraction of Liriope platyphylla in C6 and primary astrocyte cells. Biol. Pharm. Bull. 27, 1257-1260.

Ikegaya, Y., Ishizaka, Y., Matsuki, N. (2002). BDNF attenuates hippocampal LTD via activation of phospholipase C: implications for a vertical shift in the frequency-response curve of synaptic plasticity. Eur. J. Neurosci. 16, 145-148.

Kafitz, K.W., Rose, C.R., Thoenen, H., Konnerth, A. (1999). Neurotrophin-evoked rapid excitation through TrkB receptors. Nature. 401, 918-921.

Kang, H., Welcher, A.A., Shelton, D., Schuman, E.M. (1997). Neurotrophins and time: different roles for TrkB signaling in hippocampal long-term potentiation. Neuron. 19, 653-664.

Kang, H.J., Schuman, E.M. (1995). Neurotrophin-induced modulation of synaptic transmission in the adult hippocampus. J. Physiol. Paris. 89, 11-22.

Kim, D.H., Hung, T.M., Bae, K.H., Jung, J.W., Lee, S., Yoon, B.H., Cheong, J.H., Ko, K.H., Ryu, J.H. (2006). Gomisin A improves scopolamine-induced memory impairment in mice. Eur. J. Pharmacol. 542, 129-135.

Kim, S.W., Chang, I.M., Oh, K.B. (2002). Inhibition of the bacterial surface protein anchoring transpeptidase sortase by medicinal plants. Biosci. Biotechnol. Biochem. 66, 2751-2754.
Korte, M., Carroll, P., Wolf, E., Brem, G., Thoenen, H., Bonhoeffer, T. (1995). Hippocampal long-term potentiation is impaired in mice lacking brain-derived neurotrophic factor. Proc. Natl. Acad. Sci. 92, 8856-8860.

Leibrock, J., Lottspeich, F., Hohn, A., Hofer, M., Hengerer, B., Masiakowski, P., Thoenen, H., Barde, Y.A. (1989). Molecular cloning and expression of brain-derived neurotrophic factor. Nature. 341, 149-152.

Lindsay, R.M., Wiegand, S.J., Altar, C.A., DiStefano, P.S. (1994). Neurotrophic factors. Trends Neurosci. 17, 182-1903.

Linnarsson, S., Bjorklund, A., Ernfors, P. (1997). Learning deficit in BDNF mutant mice. Eur. J. Neurosci. 9, 2581-2587.

Lom, B., Cohen-Cory, S. (1999). Brain-derived neurotrophic factor differentially regulates retinal ganglion cell dendritic and axonal arborization in vivo. J. Neurosci. 19, 9928-9938.

Lohof, A.M., Ip, N.Y., Poo, M.M. (1993). Potentiation of developing neuromuscular synapses by the neurotrophins NT-3 and BDNF. Nature. 363, 350-353.

Maffei, L. (2002). Plasticity in the visual system: role of neurotrophins and electrical activity. Arch. Ital. Biol. 140, 341-346.

McAllister, A.K., Katz, L.C., Lo, D.C. (1997). Opposing roles for endogenous BDNF and NT-3 in regulating cortical dendritic growth. Neuron. 18, 767-778.

Mizuno, M., Yamada, K., Olariu, A., Nawa, H., Nabeshima, T. (2000). Involvement of brain-derived neurotrophic factor in spatial memory formation and maintenance in a radial arm maze test in rats. J. Neurosci., 20, 7116-7121.

Nguyen, P.V., Kandel, E.R. (1996). A macromolecular synthesisdependent late phase of long-term potentiation requiring cAMP in the medial perforant pathway of rat hippocampal slices. J. Neurosci. 16, 3189-3198.

Rutherford, L.C., Nelson, S.B., Turrigiano, G.G. (1998). BDNF has opposite effects on the quantal amplitude of pyramidal neuron and interneuron excitatory synapses. Neuron. 21, 521-530.

Schinder, A.F., Poo, M.M. (2000). The neurotrophin hypothesis for synaptic plasticity. Trends Neurosci. 23, 639-645.

Seil, F.J., Drake-Baumann, R. (2000). TrkB receptor ligands promote activity-dependent inhibitory synaptogenesis. J. Neurosci. 20, 5367-5373.

Shimada, A., Mason, C.A., Morrison, M.E. (1998). TrkB signaling modulates spine density and morphology independent of dendrite structure in cultured neonatal Purkinje cells. J. Neurosci. 18, 8559-8570.

Thoenen, H. (1995). Neurotrophins and neuronal plasticity. Science. 270, 593-598.

Vicario-Abejon, C., Collin, C., McKay, R.D., Segal, M. (1998). Neurotrophins induce formation of functional excitatory and inhibitory synapses between cultured hippocampal neurons. J. Neurosci. 18, 7256-7271.

Yacoubian, T.A., Lo, D.C. (2000). Truncated and full-length TrkB receptors regulate distinct modes of dendritic growth. Nat. Neurosci. 3, 342-349. 